\title{
LA OPERACIÓN VUELO DE ÁNGEL, PUNTO DE INFLEXIÓN EN EL CONFLICTO ARMADO COLOMBIANO
}

\author{
María ALEJANDRA SANTOS BARÓN ${ }^{l}$
}

\section{INTRODUCCIÓN}

El conflicto armado colombiano ha estado caracterizado por los enfrentamientos entre las Fuerzas Militares y grupos al margen de la ley como las FARC, ELN y grupos de autodefensas. De esta manera, durante este conflicto se han producido diferentes puntos de inflexión. Estos puntos se pueden entender como momentos de quiebre históricos, en donde se producen cambios en las dinámicas políticas, militares, económicas y sociales; que se ven alteradas por fenómenos externos o internos. "La noción de turning point -o punto de inflexión- hace referencia a momentos especialmente significativos de cambio; se trata de eventos o transiciones que provocan fuertes modificaciones." (ROBERTI, 2012). Como lo señala James A. RAWLEY, los puntos de inflexión, "sugieren coyunturas importantes en el curso de la historia, cuando la fuerza se encuentra con otra contra fuerza con tal intensidad, como para hacer posible un cambio.” (RAWLEY, 1967, p. 1) Igualmente, en los años noventa, se produjeron diferentes puntos de inflexión como los ataques de las Delicias, El Billar, la toma de Miraflores y la toma de Mitú.

Durante la década de los años noventa, Colombia vivió una época de violencia, caracterizada por los enfrentamientos violentos entre las Fuerzas Militares y los grupos al margen de la ley. Igualmente, en el transcurso de esta época el Estado colombiano tuvo problemas para consolidar su aparato estatal, ya que, al disputarse y enfrentarse con grupos al margen de la ley, el monopolio de la violencia legítima estaba debilitado.

\footnotetext{
Magister en Seguridad y Defensa Nacional de la Escuela Superior de Guerra, Politóloga del Colegio Mayor de Nuestra Señora del Rosario. Actualmente trabaja en la Fuerza Aérea Colombiana, en el Departamento Estratégico de Asuntos Jurídicos y Derechos Humanos. Es miembro del grupo de investigación "Análisis en Contexto". Este capítulo se basó en el trabajo de grado de la autora, para obtener su título profesional como politóloga. Agradecimientos especiales para el General Yair Perdomo, quien colaboró en la investigación.
} 
Los ataques a las Delicias, el Billar, la Toma de Miraflores y la Toma de Mitú, demostraron la debilidad estatal y constituyeron duros golpes a las FF.MM. Estos ataques corresponden a una estrategia política militar de la guerrilla para consolidar su poder territorial en el sur del país, con el propósito de crear un corredor estratégico de movilidad hacia las fronteras con Brasil y Venezuela. Sin embargo, con la respuesta de las FF.MM, en cabeza de la Fuerza Aérea bajo la Operación Vuelo de Ángel, se logró frenar la estrategia militar de la organización ilegal.

De esta manera, la Operación Vuelo de Ángel (O.V.A) realizada por la Fuerza Aérea Colombiana fue uno de los puntos de inflexión en el conflicto armado colombiano, esto por el poder aéreo utilizado que logró alterar las asimetrías entre las FF.MM y la organización ilegal. Esta operación frenó el paso de la guerra de guerrillas a la guerra de movimientos, siendo esta una asimetría que favorecía a la guerrilla. Así, el presente artículo pretende analizar por qué la Operación Vuelo de Ángel, puede considerarse como uno de los puntos de inflexión del conflicto armado colombiano.

El capítulo está divido en los siguientes apartados: en la primera parte, se explicarán los años noventa en el conflicto armado; y en la segunda parte, se analizará en qué consistió la Operación Vuelo de Ángel. Esta última parte consta de tres subpartes: la primera, la toma de Mitú; la segunda, la O.V.A y la tercera, después de la Operación.

La pregunta planteada para la investigación fue, ¿Por qué puede considerarse la Operación Vuelo de Ángel como el punto de inflexión del conflicto armado colombiano, teniendo en cuenta que esta operación cambio la asimetría de poder entre las FFMM y las FARC?

El presente capítulo cuenta con una investigación claramente cualitativa, en donde se escogió la tipología de estudio de caso. Esta metodología permite el estudio y análisis de un caso específico, encontrando las particularidades del mismo. Igualmente se manejará este método de investigación, en donde "se utilizan las descripciones interpretativas (palabras) más que estadísticas (números) para analizar los significados subyacentes y patrones de relaciones sociales." (Universidad de Valencia, s.p.).

El enfoque que se va a privilegiar en la investigación, es el enfoque neo institucionalista ya que este permite entender los fenómenos políticos mediante el estudio de las instituciones, así "la investigación de los fenómenos políticos parte de las instituciones, como rasgo estructural de la sociedad, o de la forma de gobierno. Sin embargo, se postula que este análisis debe estar también informado por un escrutinio del comportamiento individual, las ideas y los intereses en juego, tanto individuales, como grupales." (LosAda y CASAS, 2008, p. 179). En ese sentido, en el artículo se analizarán las instituciones y las relaciones de poder 
del Estado, las Fuerzas Militares, y la organización ilegal FARC, entendida como una organización al margen de la ley.

En este marco, "El resultado de la investigación podrá ser pertinente para el Estado Colombiano, especialmente para las Fuerzas Militares ya que este estudio les permitirá tener una investigación académica sobre el poder aéreo y su influencia en la alteración de la asimetría. Así mismo, esta investigación es relevante porque permite analizar una operación militar que resulta exitosa para el Estado Colombiano. Igualmente, este trabajo resulta pertinente para la ciencia política en la medida en que permite relacionar un concepto militar con un concepto académico, y permite entender las relaciones de poder que se presentaron entre la organización ilegal y el Estado colombiano." (SANTOS, 2014, p. 10).

Teniendo en cuenta la coyuntura actual de Colombia, en donde se presenta un proceso de paz con la guerrilla, es necesario evaluar las operaciones más relevantes del conflicto armado interno colombiano, ya que se pueden identificar los escenarios disuasorios, en donde por medio de la acción militar se logra hacer retroceder a la guerrilla.

\section{LOS AÑOS NOVENTA EN EL CONFLICTO ARMADO COLOMBIANO}

La época de los años noventa presentó una dinámica violenta dentro del contexto del conflicto armado colombiano, por los fuertes enfrentamientos que se presentaron entre las FFMM, las organizaciones ilegales como las FARC, ELN y las autodefensas. Igualmente, es en este tiempo que la guerrilla FARC, logra ejecutar ataques estratégicos en el sur del país.

Durante los años noventa, las Fuerzas Militares recibieron duros golpes contra sus Batallones, Brigadas, Puestos de Control, Puestos de Policía, entre otros. Los ataques militares a las Delicias, el Billar, Miraflores fueron parte de un planeamiento estratégico de la organización ilegal para crear un corredor hacia la frontera de Venezuela y Brasil. Esto con el propósito de mantener un control territorial en el suroriente del país.

Un factor fundamental en el incremento de los ataques militares perpetuados por las guerrilla en los noventa, fue el aumento de los cultivos de coca. "Colombia (...) paso a tener más de 100 mil hectáreas en 1995 y 150 mil hectáreas en 1996. Esta nueva actividad, que transformó el papel de Colombia en el negocio de la coca, también modificó la guerra de guerrillas (...) Las áreas de expansión de la coca fueron las selvas del sur, donde los grupos más significativos de las FARC tenían asiento." (PARDO, 2008, p. 626) De esta forma, se puede evidenciar la relación entre los cultivos de coca y la presencia de las FARC, en el sur de país. "La nueva fuente de recursos les dio a las FARC un nuevo horizonte 
político-militar y una nueva base social. La financiación le permitió a este grupo armado, en particular a los llamados bloques de frentes Oriental y Sur, aumentar numéricamente e incrementar sustancialmente su capacidad militar." (PARDO, 2008, p. 626) Con el crecimiento de las finanzas de la guerrilla impulsadas por el narcotráfico, fortalecen su capacidad económica para planear los ataques y movilizar su pie de fuerza en el sur del país.

Por iniciativa de la Fuerza Pública, en el Gobierno de Cesar Gaviria, se lanza el ataque contra Casa Verde, uno de los "santuarios de las FARC" y donde se encontraban los miembros del Estado Mayor de la organización ilegal. "Los combates por iniciativa de las Fuerzas Militares se incrementaron en virtud de la llamada "guerra integral contra la guerrilla" lanzada tras el fracaso de los diálogos de paz con la Coordinado Guerrillera Simón Bolívar(CGSB).” (EchANDía, 2008, p. 6). En el ataque contra Casa Verde se utilizaron diferentes recursos militares como helicópteros, aeronaves K-fir entre otros. "Al cabo de intensos bombardeos con aviones de guerra, tropas del Ejército asumieron ayer el control del área de influencia guerrillera en La Uribe y avanzaban ayer hacia Casa Verde, cuartel general de las Fuerzas Armadas Revolucionarias de Colombia (FARC)" (El Tiempo, 1990).

Más adelante, "durante el gobierno de Ernesto Samper (1994-1998), las FARC, que ya contaban con una mayor capacidad ofensiva derivada de la acumulación de experiencia en la preparación y conducción de ataques, escalaron su accionar con el propósito de dar el salto de la guerra de guerrillas a la guerra de movimientos." (EChANDÍA, 2008, p. 6). Un ejemplo de esto fueron los ataques de las Delicias, el Billar, y la Toma de Miraflores.

De esta forma, en 1996 se produce el ataque en las Delicias (Caquetá), contra una base militar del Ejército. "Era la primera vez que una compañía, establecida en una base previamente fortificada, con armamento y equipo completo, con adecuado entrenamiento general era totalmente destruida."(PARDO,2004, p. 632)2. Este ataque de la organización ilegal era con "fuego nutrido de ametralladoras, granadas de fusil y de mortero. Decía el operador de radio que el ataque principal lo estaban dirigiendo con artillería pesada, probablemente se refería a cilindros de gas, rellenos de explosivos y metralla." (PARDO, 2004, p. 628). Con este ataque las FARC demostraron a las Fuerzas Militares sus capacidades bélicas ${ }^{3}$.

Por otra parte, el éxito de esta operación de la guerrilla, radica "en el dominio de la zona, tanto de los ríos como de los caminos en la selva, del conocimiento de la situación y de los movimientos de las unidades militares, de su capacidad de reunir cuatrocientos hombres, sin ser detectados por la inteligencia militar, y de esperar el momento adecuado para realizar el golpe de mano." (Pardo, 2008 , p. 631). Esta operación, refleja el paso de las guerras de guerrillas a la guerra de posiciones, en la medida en que las FARC, realizan un ataque prologando, con un pie de fuerza relativamente alto, y el enfrentamiento contra la Compañía del Ejército fue con artillería pesada.

3 Como lo menciona Rafael Pardo, "las operaciones desplegadas por estos dos bloques de frente de las Farc, tuvieron desde 1996 una característica novedosa: eran propiamente militares, con grandes unidades y teniendo como objetivos bases militares y policiales fuertemente defendidas, muy distintas a los hostigamientos, 
Otro ataque estratégico para la guerrilla fue el ataque conocido como El Billar. Éste fue realizado el $1^{\circ}$ de Marzo de 1998, en el municipio de Cartagena del Chairá (Caquetá), contra el Batallón Contraguerrillas No 52. "Esta era la primera vez que una unidad especializada en la lucha contra la insurgencia perfectamente entrenada y con mejor dotación de las FF.MM, era atacada por un actor irregular." (PARDO, 2004, p. 636).

Después del ataque de El Billar, el 3 de agosto de 1998, se produce lo que se conoce como la Toma de Miraflores, contra la Base de Policía Antidrogas, en el municipio de Miraflores (Guaviare). Este "enfrentamiento, que duró más de 20 horas, dejó como saldo 9 muertos, 10 heridos y 22 militares desaparecidos." ( El Espectador, 2008).

Así mismo, como lo señala Camilo Echadía, "el Ejército sufrió un duro revés en su empeño por debilitar la retaguardia estratégica del bloque sur (...) las FARC atacaron las bases de la Policía en Miraflores (Guaviare) y Uribe (Meta), así como las instalaciones del Ejército en Pavarandó (Urabá); en desarrollo de estas acciones murieron cerca de 100 personas entre uniformados y civiles y fue secuestrado un centenar de miembros de la Fuerza Pública." (Echandía, 2011, p. 13). Estos ataques debilitaron a las Fuerzas Militares. Igualmente, el Estado Colombiano estaba atenuado por su poca eficiencia en el control del monopolio legítimo de la violencia. Así, "el Estado colombiano, debido a la falta de presencia en todo el territorio nacional y a la pérdida del monopolio legítimo de la fuerza, no integra ni cohesiona la población y el territorio y ha reducido su capacidad para mediar y canalizar los conflictos y tensiones sociales. Estos son resueltos al margen de las instituciones públicas, lo cual es la causa del surgimiento de diversas expresiones de "parainstitucionalidad", tales como los grupos privados de justicia y defensa, las mafias de narcotráfico y los movimientos guerrilleros.” (EsCOBAR, 1998).

Ahora bien, como lo muestra la siguiente gráfica, para 1996 las FARC ya se encontraban en la etapa de guerra de movimientos, los ataques perpetrados durante este año y hasta 1998, son el reflejo del paso de la guerra de guerrillas a la guerra de movimientos. Esto se debe a la estrategia militar de la guerrilla de propiciar golpes a unidades militares, durante un tiempo prolongado,con armamento pesado y utilizando una cantidad alta de combatientes. Así, dejan las emboscadas, y los ataques de repliege, para pasar a un enfrentamiento prolongado con las Fuerzas Militares. Los casos mencionados anteriomente, de los ataques a las Delicias, El Billar, Miraflores reflejan precisamente ese cambio de estrategia.

emboscadas o asaltos a pequeñas unidades, que había predominado en las tres décadas anteriores." (Pardo, 2008, p. 626). En este orden de ideas, a partir del año 1996, las FARC ponen en práctica, su modo de operar, (ubicación, detección, asedio y copamiento) para atacar unidades militares. 
Gráfico 1. Etapas de la Guerra Popular Prolongada de las FARC-EP.

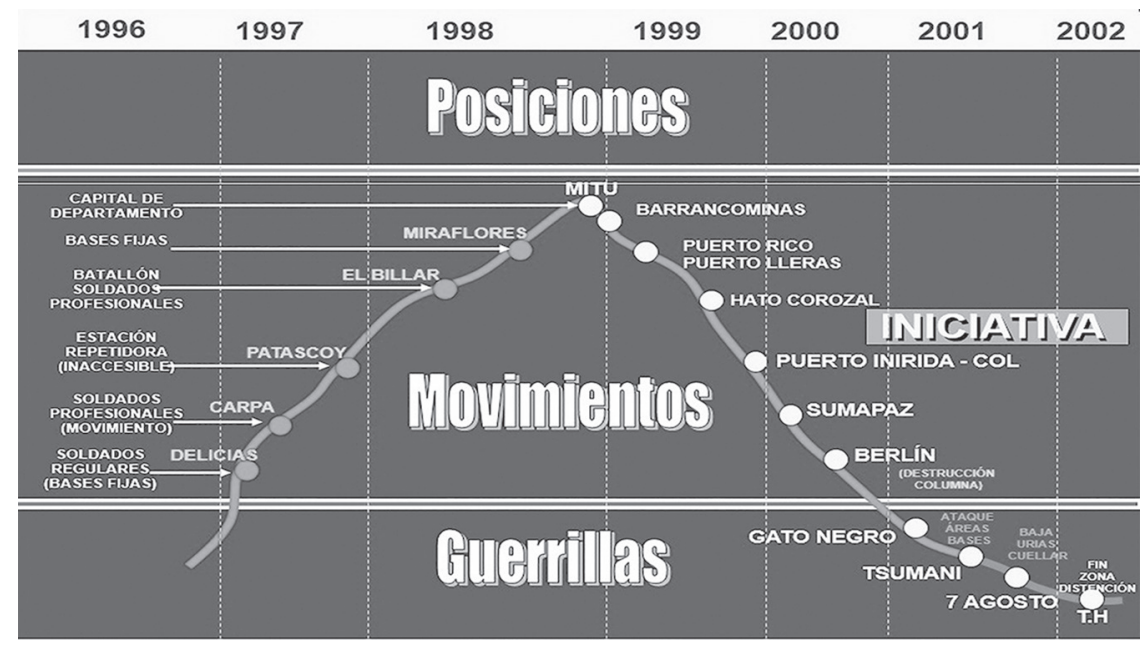

Fuente: (Santos, 2014, p. 19)

El Bloque Oriental de las FARC en "1993 se le asignó un área de injerencia que comprendía nueve departamentos: Cundinamarca, Boyacá, Arauca, Casanare, Vichada, Meta, Guaviare, Guainía y Vaupés.” (Paz, 2015, p. 5). Teniendo en cuenta que este Bloque fue el que lideró los ataques de las Delicias, El Billar,Miraflores y Mitú, se puede deducir que su apuesta de control territorial estaba enfocada a la creación de un corredor de movilidad hacia las fronteras de Brasil y Venezuela. Respecto a esto, el Gr Perdomo menciona que "de esta forma todos esos puntos (Miraflores, Carurú, las Delicias, el Billar) eran lanzas que estaban dirigidos, hacia la frontera con Brasil y Venezuela". (SANTOS, 2014, p. 65).

Prueba de ello es la ubicación geográfica de los municipios de Puerto Leguizamón, Putumayo (Delicias), Cartagena del Chaira, Caquetá (El Billar), Miraflores, Guaviare, y Mitú, Vaupés. Al trazar una línea entre estos municipios se puede deducir que el control territorial de éstas, era fundamental para la organización ilegal, para así tener un corredor de movilidad. Si lograban mantener esos territorios, tenían controlado una parte importante del sur del país, el siguiente mapa muestra el trazo de "la línea estratégica de control de las FARC"

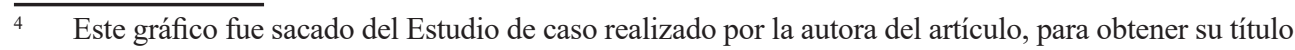
como Politóloga, con base a una entrevista que se le realizó al General Perdomo. 


\section{Mapa 1. Corredor Estratégico de las FARC 1996-1998}

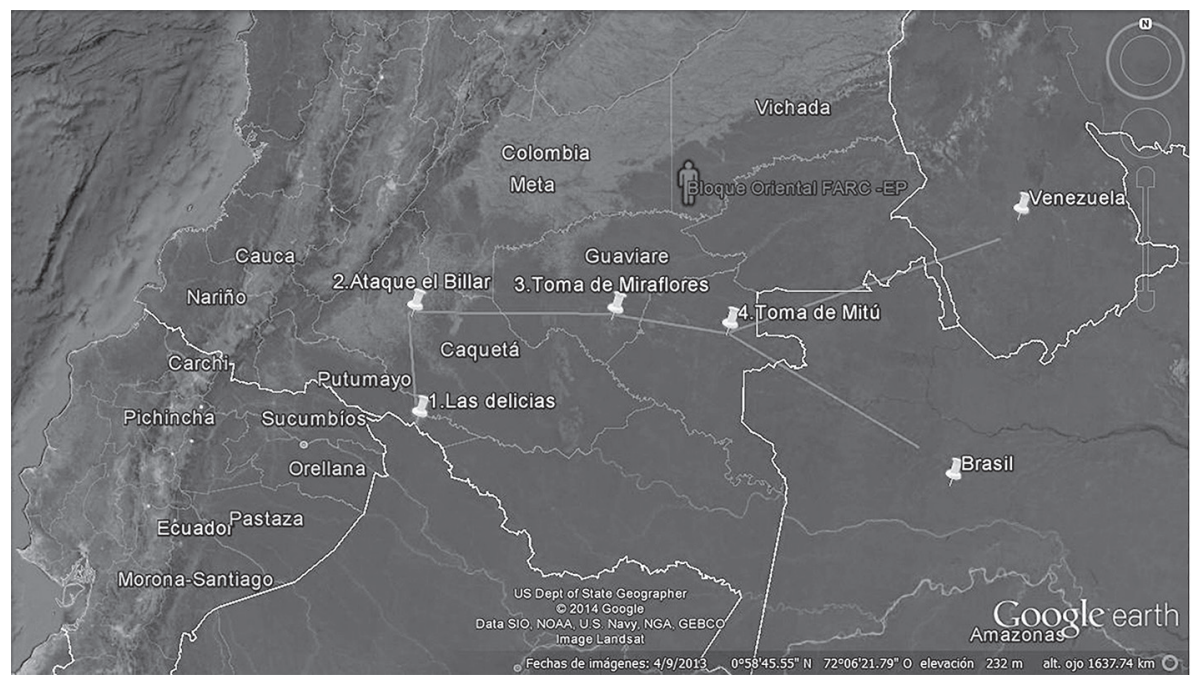

Fuente: (Santos,2014, p. 23).

Por otra parte, mientras por la vía militar se apoderaban de esos territorios, por la vía política conseguían otros. Cuando se inicia el proceso de paz del Gobierno del Presidente Andrés Pastrana, las FARC solicitan el despegue de varios territorios en el departamento del Metá. "El pedido hecho por las Farc a comienzos de 1998, de desmilitarizar los municipios de San Vicente del Caguán, la Uribe, Mesetas, La Macarena y Vista Hermosa, como requisito para iniciar conversaciones de paz, fue ratificado a mediados del año y aceptado por Pastrana, como presidente electo.” (LeAL, 2002, p. 150). Vale la pena aclarar que más adelante se va a retomar este punto.

En conclusión, la década de los años noventa fue violenta por los ataques producidos por la organización ilegal en diferentes zonas del país, sobre todo en el sur, con los ataques a las Delicias, El Billar, y Miraflores. Estos son otros puntos de inflexión que marcaron la época de los años noventa. Ahora bien, la guerrilla siguiendo los planteamientos estratégicos de las Conferencias, y bajo la tesis de la guerra popular prolongada se encuentran en la etapa de la guerra de movimientos, los ataques en esta época son precisamente un reflejo de este ciclo. Para 1998, Colombia vivía uno de los períodos más violentos de su historia. Con los ataques producidos, la organización ilegal pretendió crear un corredor de movilidad en el sur del país, con salida hacia las fronteras, para tener un control territorial que le aseguraba el tránsito de tropas, y el tráfico de drogas ilícitas. 


\section{LA OPERACIÓN VUELO DE ÁNGEL}

El siguiente apartado se enfoca en analizar la Operación Vuelo de Ángel (O.V.A), entendida como la operación militar que logró alterar las asimetrías entre la Fuerza Pública, y la organización ilegal, por el poder aéreo utilizado. De esta forma, este apartado tiene tres subpartes, la primera describe la toma de Mitú, en donde se explicará en qué consistió la toma; la segunda analiza la Operación Vuelo de Ángel; y la tercera pretende explicar qué pasó después de la O.V.A, ya que esta operación se convirtió en un precedente militar para las Fuerza Pública y el Estado Colombiano.

\subsection{LA TOMA DE Mitú}

La apuesta más estrátegica de la organización ilegal, durante los años noventa, fue la Toma de Mitú. Este ataque se produjo el $1^{\circ}$ de noviembre de 1998, en la capital del Vaupés. "Con 1.200 de sus hombres, las FARC iban tras el último lugar de la amazonia cubierto por presencia policial: apostados en el puesto de policía de Mitú, 75 policías, entre oficiales, suboficiales y agentes, intentaban defenderse sin posibilidad de recibir apoyo inmediato, a pesar de estar en una capital de departamento." (Perdomo, 2006, p. 288).

Por una parte, este ataque de la organización ilegal tenía tres propósitos, el primero relacionado con línea estratégica de control territorial, mencionada anteriormente. De esta forma, controlar Mitú, era demostrarle al país que eran capaces de tomarse una capital de departamento, y dada la posición geográfica de Mitú (cercanía con la frontera de Brasil) asegurar ese territorio, era tener controlado un punto estratégico con la frontera, creando así el corredor de movilidad. El segundo propósito, era fortalecer su posición política en la mesa de conversación con el gobierno del Presidente Andrés Pastrana."Con miras a maximizar su posición negociadora con Pastrana, las Farc se tomaron la población de Mitú, capital de departamento" (PAlacios, 2012, p. 159). Por último, el tercer propósito estaba relacionado con el reconocimiento internacional del estatus de beligerancia al demostrar el control del territorio.

"La intención de la guerrilla no era solo dar un golpe efectista y salir, sino quedarse definitivamente -o por lo menos algunas semanas- en esta población, reclamando de la comunidad internacional un reconocimiento de su estatus de beligernacia, algo que quizás algunos pocos países hubieran hecho, basandose en precedentes históricos y en la terminología internacional, que se aplica a movimientos insurgentes que llegan a dominar una parte importante del territorio. Inclusive,llegamos a tener información de que allí pensaban lanzar una especie de gobierno autónomo sobre una porción de territorio para generar un hecho político.” (Pastrana, 2005, p. 93). 
En este orden de ideas, las estrategias militares y políticas de la organización ilegal, para 1998, le estaban dando resultados contundentes. Además, con la estrategia militar de la guerra popular prolongada, les permitió realizar ataques, para así fortalecer su estrategia política de la "toma del poder." Igualmente, bajo el contexto del proceso de paz con Pastrana, la guerrilla logró demostrar su poderío militar con la toma de Mitú.

"El Bloque Oriental de las FARC, integrado por los frentes 1, 7, 17, 44 y por la Columna Móvil Juan José Rondón, que sumaban no menos de mil trescientos hombres atacaron a Mitú.” (PARDO, 2008, p. 639). Esta toma, estaba liderada por Henry Castellanos, alias Romaña, y como comandante del Bloque estaba Jorge Briceño Suárez, alias Mono Jojoy. "Los guerrilleros atacaron el cuartel de Policía, y sus alrededores, en un radio de tres manzanas, que quedaron prácticamente arrasadas, utilizando armas no convencionales, como cilindros de gas rellenos con gasolina, pegante inflamable, y pentolita, además de gradanas, que lanzaban desde las mismas viviendas de los atemorizados pobladores." (Pastrana, 2005, p. 94). Las FARC eligieron Mitú porque les representaba una ventaja asimétrica ${ }^{5}$ favorable respecto a las Fuerzas Militares. "Mitú era en ese momento el punto más alejado de la geografía colombiana con una concentración importante de Fuerza Pública. Era el lugar al que podían atacar con ventaja porque los refuerzos tardarían mucho tiempo en llegar." (Perdomo, 2006, p. 289). Igualmente, otro factor que favoreció la Toma fue que "el sitio más cercano para lanzar la operación aérea era San José del Guaviare, ubicado a 180 millas de Mitú.” (Perdomo, 2006, p. 293). Por tanto, el radio de alcance de los helicópteros (200 millas) no alcanzaba para regresar a San JosÉ del Guaviare. (Perdomo, 2006, p. 293).

En Mitú la presencia estatal estaba liderada por la Policía, como lo relata John Frank Pinchao, "nosotros éramos un grupo aproximadamente de 75 policías, en su mayoría patrulleros recién egresados de las escuelas de formación policial, quienes, al contrario de lo que comúnmente se piensa -que son inexpertos y no aptos para el combate- se defendieron como tigres. Fuimos atacados por unos 1500 guerrilleros al mando del Mono Jojoy, quien delegó funciones en comandantes guerrilleros como Urías, Romana, Patesopa, y otros. La verdad no esperaba que emplearan tantos guerrilleros para esta toma, pues como lo dije, era prácticamente un pueblo tranquilo y esto no tenía antecedentes." (MARTíN y JARAMILLO, 2014).

Para efectos del concepto de asimetría se trae a colación, el concepto de Steven Metz, el cual define que la asimetría es "actuar, organizar y pensar diferente al oponente con el fin de maximizar las ventajas, explotar las debilidades del adversario, obtener la iniciativa, o alcanzar una mayor libertad de acción. Ésta puede ser estrategia-política, estrategia militar o una combinación de ambas." (Metz y Johnson II, 2001). 


\title{
2.2. La Operación Vuelo de Ángel
}

Ahora bien, para contrarrestar la Toma de Mitú, las Fuerzas Militares lanzan la Operación Vuelo de Ángel (O.V.A). Ésta consistió en el apoyo aéreo a los Policías y el ataque aéreo a posiciones de la organización ilegal. El poder aéreo ${ }^{6}$ se vio reflejado en la utilización de aeronaves de ala fija (AC-47 Fantasma, C130 Hércules, OV -10 Bronco, T 27 Super Tucano, C235) y aeronaves de ala rotatoria (Helicópteros Black Hawk y Arpia). En ese sentido "la primera decisión que tomaron las FF.MM, fue enviar un avión fantasma AC-47 y 2 aviones OV -10 Bronco, para que estos realizaran los primeros bombardeos, y sirvieran como apoyo aéreo para los policías que estaban en Mitú." (SANTOS, 2014, p. 37). Igualmente, para retomar Mitú, los Generales Freddy Padilla de León, Comandante de la VII Brigada del Ejército, el General Jaime Humberto Cortés Parada, Comandante de la Cuarta División, junto con el entonces Coronel Perdomo, Comandante de CACOM 4, empezaron a planear la operación.

En el momento en que la organización ilegal se tomá Mitú, las FFMM realizan un cálculo estratégico de la importancia de recuperar la capital.Respecto a esto el Gr (r) Perdomo comenta:

\begin{abstract}
"Cuando comenzamos a valorar todo y a realizar el análisis durante el ataque a Mitú nos dimos cuenta que ellos ya tenían todo preparado, atacaron La Uribe, el Billar, y las Delicias, hicimos la flecha trazando estos puntos y nos preguntamos esta gente para donde va. Cuando atacan Miraflores, usted mira la cronología y se da cuenta que ellos estaban caminando y nosotros no nos dimos cuenta. Entonces cuando dicen Mitú, nos dimos cuenta que o vamos por Mitú o perdemos media Colombia, que era parte del plan de las FARC. Cuando se presentó esta situación, nos dimos cuenta que teníamos que salvarle la vida a la gente y al Estado.” (SANTOS, 2014, p. 65).
\end{abstract}

Por parte de la Fuerza Aérea Colombiana (FAC), "el Comando de la Fuerza Aérea dispusó de cuatro Black Hawn, dos UH-60 de transporte y dos tipo Arpía de ataque, tres aviones fantasma, tres OV -10, un Tucano T-27, y dos Hércules c-130" (RUEDA, 2008, p. 640). El apoyo aéreo prestado por el Avión Fantasma fue fundamental, para disminuir la intensidad del ataque, sin embargo, para el $1^{\circ}$ de noviembre en la tarde, los policías "que resistian en el puesto se entregaron ante la superioridad de los atacantes" (PARDO, 2008, p. 640). Un factor que disminuyó la efectividad del poder aéreo fue que para ese entonces, las Fuerzas Militares no tenían cartografía de Mitú, por tanto al momento de lanzar los bombardeos, no había mucha precisión, y se podía afectar a la población civil. "Habíamos olvidado a Mitú, no teníamos mapas discriminados por cuadrantes, ni grillas del terreno para que los policías en tierra pudieran darnos instrucciones precisas."' (PERDOMO, 2006, p. 294).

El poder aéreo es "el uso militar de recursos aeroespaciales para defensa de la nación y apoyar su política extranjera. Más aún, es la aplicación de instrumentos aeroespaciales para el logro de los objetivos del liderazgo nacional." (Ogan, 1991). 
Sin embargo, ese problema se resolvió cuando por instrucciones del General Perdomo, se realizó un mapa con indicaciones de personas que conocían la capital y lo complementaban cuando las tripulaciones regresaban. (Perdomo, 2006, p. 295). "Para contrarrestar esta dificultad, el entonces Coronel Perdomo, quien dirigió la operación, mandó llamar a un agente de la policía que había estado en Mitú y por esta razón conocía la capital. Así, éste le hizo un mapa de Mitú, ubicando el Hospital, el colegio, el puesto de policía, entre otros." (SANTOS, 2014, p. 37).

Estos mapas se crearon bajo la denominación de grillas, como lo menciona el Gr Perdomo:

"Se nos presentó un problema relacionado con la precisión de los ataques. Así,
cuando la Policía nos pedía apoyo, mire que nos estaban disparando desde la
Iglesia, pero uno alcanzaba a ver la punta de la Iglesia, pero no sabíamos cuál
era. Entonces qué nos tocó hacer, nos inventamos en Apiay, una cosa que se
llama las grillas, entonces tomábamos las fotos de los pueblos y lo dividíamos
en cuadros. Así, a cada puesto de Policía, le entregamos una foto con las grillas,
y nosotros teníamos otra. Por ejemplo, cuando atacaban un pueblo, la Policía
decía me están atacando el Cuadro C, y nosotros cuadriculamos las fotos. Ellos
nos decían el cuadro y nosotros aquí lo dibujamos, entonces sabíamos a donde
mandar el ataque exactamente. Así, todos teníamos esos mapas y cuando nos
pedían el apoyo, nosotros sabíamos dónde actuar". (SANTos, 2014, p. 65).

Sin embargo, para el caso de Mitú no tenían estas grillas al iniciar la Operación, ya después se fue configurando el mapa, como se muestra en el siguiente mapa que realizaron policías y pilotos para la retoma de Mitú.

\section{Mapa 2. Mapa de Mitú en Grillas}

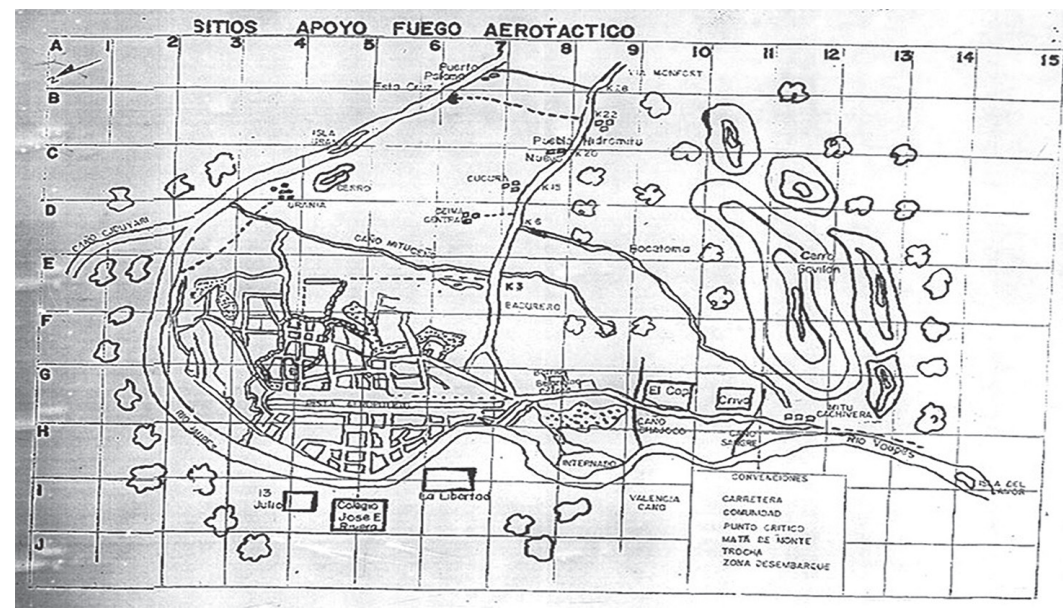

Fuente: (Perdomo, 2013, p. 23) ${ }^{7}$

\footnotetext{
7 Gráfica proporcionada por el General Yair Perdomo.
} 
Como no había una pista aérea cercana a Mitú, las Fuerzas Militares, utilizaron una pista en la frontera de Brasil. "Era una pista construida por el gobierno brasilero para ejercer soberanía de frontera y que tenía unos ochocientos o mil metros de largo. Pensaba que allí podríamos aterrizar aviones Hércules C 130, aviones Caza 235 y los helicópteros uh-60 de transporte y de combate." (Perdomo, 2006, p. 296). Esta pista fue una ventaja para las FFMM en la medida en que les permitió desplegar todo el poderio aéreo, resbastecerse y pernoctar, fue desde allí que los Hércules, los Helicópteros Black Hawk, y los OV 10 lanzaron la Operación. Respecto a esto el Gr Perdomo comenta que "no teníamos una pista entre San José del Guaviare y Mitú para transportar los aviones, entonces tuvimos que tramitar un permiso para utilizar una pista que hay en la frontera en Brasil. Una de estas pistas era Itibare esta quedaba a 70 millas a distancia al Sur, quedaría a 280 millas, entonces no podíamos llegar. Igualmente, ellos nos estaban haciendo un monitoreo y estaban escuchando nuestra frecuencia y cuando nos dimos cuenta el operador de radio de las FARC-EP, nos dice jaquí nos vamos a quedar! Eso nos motivó más." (SANTOS, 2014, p. 68).

"Las FARC-EP realizaron un cálculo estratégico basado en las distancias entre Mitú, y los lugares en los cuales se podría lanzar una operación. Sin embargo, no contaron con que las FF.MM encontrarían una pista en Brasil, en donde pudieron aprovisionar a los aviones y helicópteros. Entonces, el cálculo estratégico se convirtió en una asimetría de poder que era una ventaja para las FARC-EP y una debilidad para las FF.MM.” (SANTOS, 2014, p. 42). Sin embargo, cuando se utilizó la pista en Brasil, este asimetría se alteró terminando por favorecer a la Fuerza Aérea. De esta manera, se puede evidenciar que cuando el Estado combina su poder nacional, en este caso la diplomacia, con el poder militar, puede alterar las asimetrías y así maximizar una debilidad de la organización guerrillera.

Mientras la tropa de Ejército se transportaba hacia la pista en Querari, Brasil, "El avión Fantasma detectó a los guerrilleros de las FARC que se reagrupaban, organizaban cordones de seguridad y se movian por río y por tierra. Bajo un incesante bombardeo, la Fuerza Aérea dio de baja un número importante de subversivos, la retoma apenas comenzaba" (PERDOMO, 2006, p. 302). Uno de los instrumentos aeroespaciales que fue clave en la Operación Vuelo de Ángel, fue el avión fanstasma este "era el más importante, porque era el que tenía mayor duración de tiempo, y en ese avión podíamos meter a gente para que hiciera monitoreo de comunicación. Ellos escuchaban todo lo que pasaba y nos ayudaban a orientar, porque no teníamos equipos de interceptaciones de comunicaciones. El fantasma tenía un sistema que se llamaba FLIR, y con este sistema podíamos ver los movimientos de la guerrilla." (SANTOS, 2014, p. 70).

Uno de los factores de éxito de la Operación Vuelo de Ángel, radica en la utilización de las capacidades inherentemente estratégicas del poder aéreo como lo son la velocidad, la flexibilidad, la maniobrabilidad para atacar los 
centros de gravedad del enemigo. Esto se ve reflejado en O.V.A en la medida en que el avión fantasma pudo bombardear posiciones de la guerrilla.También con la utilización de la pista en aérea en Brasil, esto les permitío tener mayor flexibilidad y maniobrabilidad. En ese sentido, "el poder aéreo tiene una serie de ventajas asimétricas (capacidades a las que el enemigo no se puede enfrentar con paridad ni contrarrestar de ninguna forma). Por ejemplo, la capacidad del poder aéreo de llevar a cabo ataques de precisión en todo el mundo puede desempeñar una función importante en las operaciones de contrainsurgencia." (PECK, 2007). Igualmente, respecto al poder aéreo, como lo menciona Hayward "sus contribuciones más significativas son, probablemente, en los ámbitos de la movilidad, inteligencia y la conciencia de la situación"8. (HAYWARD, 2009, p. 14).

Así mismo, "cuando la guerrilla pasa a la guerra de movimientos y se agrupa en grandes unidades militares, queda expuesto al poder aéreo. Por tal razón, en esta etapa de la guerra popular prolongada es que el poder aéreo logra ser más efectivo, porque el enemigo está agrupado en grandes unidades y está expuesto a los ataques que el poder aéreo logre efectuar." (SANTOS, 2014, p. 34). De esta forma, en Mitú cuando la organización ilegal se agrupó quedó expuesta a los bombardeos y ametrallamientos que realizó la Fuerza Aérea.

Una de esas ventajas asimétricas es que "cuando se producía un bombardeo del Avión Fantasma, este logra atacar el centro de gravedad de las FARC-EP, porque el poder aéreo demostrado ofrece "la capacidad de perseguir directamente objetivos." (VARGAS 2010, p. 25). Así, cuando se identificaba un objetivo, el avión podía lanzar un bombardeo y generar muchas bajas, porque el enemigo estaba concentrado en un solo lugar. Así mismo, el poder aéreo tiene la capacidad de alterar la asimetría de poder, ya que por sus características particulares tales como la flexibilidad, la versatilidad, la movilidad y la respuesta, logran que exista superioridad aérea y se logra atacar los centros de gravedad." (SANTOS, 2014, p. 43).

Igualmente, esta "asimetría que aprovecharon muy bien las FF.MM, fue el poder aéreo ya que les permitió obtener una ventaja en el teatro de operaciones. En la Operación Vuelo de Ángel, el uso de los helicópteros y aviones de ala fija, fueron vitales para retomar la capital del Vaupés. Así, las FF.MM utilizaron helicópteros Black Hawk UH-60 y helicópteros AH-60 Arpía, que se utilizan para combate. También utilizaron el avión AC-47 Fantasma, que proporcionó apoyo aéreo; el avión C-130 Hércules, y el avión Caza 235 para el transporte de las tropas; aviones OV-10 Bronco para el combate y apoyo aéreo; y un avión Tucano T-27 para la retransmisión de las comunicaciones." (SANTOS, 2014, p. 43).

Para el 2 de noviembre de 1998, con el constante apoyo aéreo del Avión AC-47 Fantasma y los OV-1O, ya se preparaba el desembarco en Mitú para recuperar la

$8 \quad$ Cita traducida del inglés por la autora. 
capital. Así como lo menciona el Gr Perdomo "completamos un contingente de 270 soldados en Querarí (...) le pedí al Capitán Garzón que usará una zona de desembarque a más de cinco millas del pueblo y desplegará la primera oleada de la operación, cerca de Mitú para retomar la población" (PERDOMO, 2006, p. 301). Con el trabajo conjunto y coordinado entre el Ejército Nacional, la Fuerza Aérea y la Policía, las Fuerzas Militares se preparaban para el desembarco. De esta forma, con los helicópteros Arpía se atacó a las FARC con el propósito de ablandarlos, "a las 11:30 de la mañana terminó el desembarcó de 250 soldados, y la 1:20 de la tarde, empezaron los combates entre la guerrilla y el Ejército. Las FARC calcularon las distancias y ubicaron 35 emboscadas" (Perdomo, 2006, p. 303).

Finalmente, el 3 de noviembre, "el AC-47 ubicó, a través del sistema FLIR, (...) un grupo grueso de guerrilleros que huía de Mitú por el río, les hundimos un bongo y dimos de baja a un gran número de ellos." (Perdomo, 2006, p. 305). Igualmente, "el fantasma ubicó otra columna guerrillera y fue en este ataque donde hizo un mayor número de bajas. Para el académico español de la Universidad de los Andes, Román Ortiz, especialista en guerra de guerrillas (...) ese bombardeó acabó todo el frente 37 de las FARC, aproximadamente ochenta guerrilleros." (PERdOMO, 2006, p. 306). El hecho de acabar en un solo bombardeo con casi todo un frente, es un indicador de la efectividad del poder aéreo. Es quizá por esta razón que la guerrilla se percató de las debilidades de concentrarse en grandes unidades, porque quedaban totalmente expuestas.

Respecto a esto, el General Perdomo en una entrevista señala que "la gente que estuvo en Mitú nos contó que la Guerrilla utilizó tres volquetas de obras públicas, para sacar a sus muertos porque ellos no los dejan. Se presentaron tantos muertos, porque yo sabía dónde estaba la guerrilla, yo sabía dónde era el sitio de concentración, desembarco y donde estaban las lanchas. A raíz de eso, simplemente verificamos y mandamos el ataque. Por eso fueron tantos muertos. El impacto mundial fue grandísimo, porque era una capital de departamento, pero la gente no sabía que Mitú era pequeño. Se tomaron el Estado, la cabecera del Vaupés, entonces eso impacta. Tenían ya San José del Guaviare, y se tomaron Mitú, para crear la República independiente de Marquetalia.” (SANTos, 2014, p. 70).

Como bien se sabe, para este año 1998, la guerrilla estaba tratando de demostrar su poderío militar. Con la Operación Vuelo de Ángel se revierte su estrategia militar de pasar a la guerra de movimientos, y las devuelve a la primera etapa de la guerra popular prolongada, la guerra de guerrillas. (ver gráfico 1) Es quizá por esta razón, que la O.V.A se convierte en uno de los puntos de inflexión del conflicto armado colombiano, ya que gracias al poder aéreo utilizado, las FFMM lograron alterar y cambiar la estrategia militar de las FARC. En este sentido, el Gr Perdomo afirma que: 


\begin{abstract}
"Mitú representó el punto de quiebre de la ofensiva guerrillera y el momento en el cual las FARC entendieron que teníamos la voluntad suficiente para enfrentarlos en cualquier lugar de la geografía colombiana, de día o de noche. Después de Mitú ellos tuvieron que volver a su esquema de guerra de guerrillas y al terrorismo, porque su estrategia de juntar muchos guerrilleros los exponía a grandes bajas por cuenta del poder aéreo.” (PERDOMO, 2006, p. 306).
\end{abstract}

Igualmente si se analiza la correlación de fuerzas para esa toma, el uso de las aeronaves de ala fija y de ala rotatoria, ${ }^{9}$ que fueron 23 , con la inexistencia de una capacidad de contrarrestar el poder aéreo por parte de la guerrilla para el año de 1998, esta correlación favorece positivamente a las FFMM. "La subversión desde hace varios años busca revertir la desventaja estratégica en la que quedó cuando la Fuerza Aérea modernizó su flota de aviones y helicópteros de reconocimiento y combate, al tiempo que el Ejército, la Armada y la Policía también fortalecieron sus divisiones de aviación. Todo eso le ha permitido al Estado penetrar en zonas consideradas casi como "santuarios" de la guerrilla y del propio "Secretariado." (Siglo, 2012). Sin embargo, como lo señala el General (r) Héctor Fabio Velasco, ex Comandante de la FAC "En 1999 las FARC adquirieron en un país centroamericano unos misiles de éstos, pero ese armamento requiere una preservación muy especial en un ambiente seco y frío, en la selva o en climas tropicales no se conservan bien, porque se dañan muy fácilmente" (Siglo, 2012). De esta forma, se puede evidenciar como después del 1998, las FARC empiezan a tratar de conseguir misiles tierra-aire para compensar esa debilidad estratégica de la guerrilla.

Una asimetría que benefició a la organización ilegal fue el pie de fuerza, "por una parte las FARC-EP contaban con aproximadamente mil doscientos hombres (Perdomo, 2006, p. 288), que pertenecían al Bloque Oriental compuesto por los Frentes 1, 7, 17, 44, y por la Columna Móvil Juan José Rondón. (PARDO, 2004, p. 639). A diferencia de la Policía que contaba con 75 policías, entre oficiales, suboficiales y agentes. Ahí se puede evidenciar una asimetría que favorece a las FARC-EP pues en la toma, contaban con mayor pie de fuerza que las FF.MM. Ahora bien, cuando las FF.MM lanzan la operación, "la respuesta del Ejército provino de los batallones de contraguerilla 7, 52, 53 y 54 con un total de mil doscientos hombres." (Río 2008, p. 345). Eso sin contar que se alteró la correlación de fuerzas de la organización ilegal, por el uso de los instrumentos aeroespaciales.

Igualmente, otro factor que favoreció a las Fuerzas militares es ese miedo que tiene la organización ilegal hacia los helicópteros y aviones. De esta forma, el General Perdomo comenta que:

$9 \quad$ En total fueron utilizados 23 aeronaves, entre las cuales se encuentra "Helicóptero U-60 Black Hawk, Helicóptero UH60 Arpia, Avión AC-47 “Avión Fantasma, Avión C130 "Hércules”, OV -10 Bronco, Avión C235, y avión T-27 Tucano" Esta información fue rastreada de fuentes bibliográficas, recursos de internet como la página web de la Fuerza Aérea Colombiana y de conversaciones telefónicas y entrevistas con el Gr Yair Perdomo Alvarado. 
"Los próximos ataques los hizo distantes: me atacó la Uribe, me atacó Puerto Lleras, Puerto Rico, y me atacó un puerto por allá que se llama Hato Corozal, entonces comenzó a medirme todas las fuerzas, yo tenía aviones en la base de Marandua, y en Tres esquinas. Posterior a eso, cuando yo oigo "teléfono rojo", pienso que este me va a atacar y yo no tengo ningún avión, entonces se me ocurrió que los aviones de entrenamiento volarán la zona. Así que les dije a unos instructores de entrenamiento, que volarán diferentes zonas, entonces cada uno iba a volar por diferentes zonas. Por allá estaban hablando, porque la triangulación de los radios, daba que estaban allá. Entonces cuando oímos las triangulaciones, nos dimos cuenta que iban a hacer los ataques en esos puntos: en Saravena, Puerto Lleras, Orito, Uribe y Puerto Rico, me iba a hacer cuatro jugadas. Por lo tanto, yo les dije vamos a hacer lo siguiente, váyanse y vuelan sobre estos pueblos, uno tiene que estar en el punto a las siete, el otro a las seis y media, usted a las seis y cuarenta, usted a las cinco, y usted a las cinco y media. Entonces comiencen a hablar entre ustedes, porque él los va a estar escuchando, digan lo que quieran pero digan que van a atacar, que están esperando la autorización para atacar. En la conversación, el "Mono Jojoy" dice cancelamos la situación y nos vamos por estafetas y aplazamos la estrategia.” (SANTOS, 2014, p. 45).

Por otra parte, el uso de los instrumentos aeroespaciales, generó una ventaja positiva para FFMM ya que por los bombardeos y los ametrallamientos, se logró dar de baja a una cantidad considerable de guerrilleros, como se señaló anteriormente. Finalmente, después de los últimos bombardeos realizados por la Fuerza Aérea en Mitú, la organización ilegal se empieza a replegar por el río Vaupés, utilizando diferentes rutas de escape. El siguiente mapa evidencia las rutas de escape de la guerrilla, cuando se estaba finalizando la Operación Vuelo de Ángel.

\section{Mapa 3. Rutas de Escape FARC}

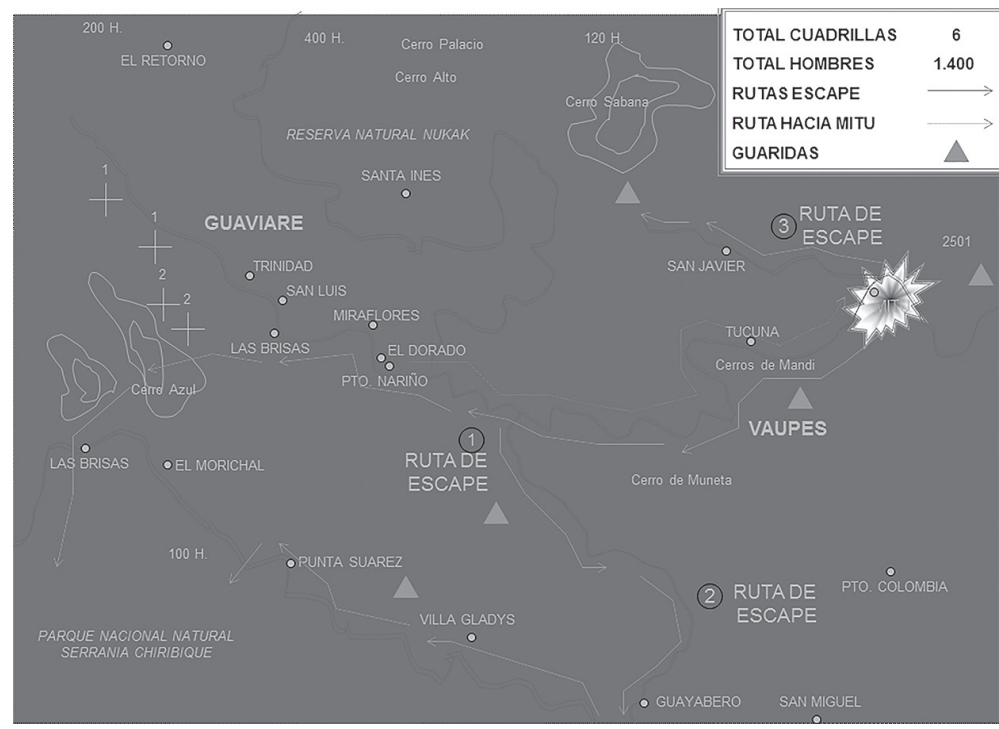

Fuente: (Perdomo, 2013, p. 11)

10 Gráfica proporcionada por el General Yair Perdomo. 
Por otra parte, en Mitú, la organización ilegal utilizando las asimetrís, empleó armamento no convencial, "habían lanzado doscientos cilindros bombas, cargados con metralla y pegamento para, de paso producir intoxicación en la tropa, a causa de la mezcla de gases." (Perdomo, 2006, p. 306). "El uso de armas no convencionales se convierte en una asimetría que utilizan las FARC-EP, para atacar al enemigo. Las FF. MM. como están sujetas al Derecho Internacional Humanitario y a los Protocolos I y II de la Convención de Ginebra, no utilizan armas que no estén reguladas por el Derecho Internacional. Esto supone una ventaja para las FARC-EP ya que al no estar sujetas en estos tratados internacionales, recurren a este tipo de prácticas para generar mayor daño.” (SANTOS, 2014, p. 44).

De esta forma como lo señala Robin GEISs "la parte más débil buscaba obtener una ventaja comparativa frente a un enemigo militarmente superior, asistimos a la reaparición de prácticas prohibidas desde hace tiempo en los conflictos armados, como son los ataques directos contra personas civiles, la toma de rehenes y el uso de escudos humanos, y a la utilización de esas prácticas como estrategia". (GeIss 2006, p. 2).

"Como saldo de la violenta incursión guerrillera, 16 civiles y 12 policías fueron asesinados, 10 policías resultaron heridos y 60 policías fueron secuestrados, incluyendo al Coronel Luis Mendieta." (PATiÑo, 2010). Eso sin contar que Mitú quedó destruida, por los cilindros que utilizó la organización guerrillera.

"La Operación Vuelo de Ángel marcó un punto de quiebre en el conflicto colombiano, porque esta operación frenó la avanzada guerrillera. Gracias al poder aéreo demostrado, se dieron de baja a muchos guerrilleros, lo cual permitió inclinar la balanza hacia el Estado colombiano. Así mismo, con esta operación se alteró la correlación de fuerzas entre las FF.MM y las FARC-EP. Esta operación "supuso un avance estratégico del Estado para materializar un objetivo perseguido desde vieja data: la presencia y el control en cualquier parte del territorio nacional." (FLÓREZ y JARAMILLO, 2014, p. 80). Igualmente, esta operación sirvió para que las FF.MM se dieran cuenta que el poder aéreo, es una ventaja que el Estado colombiano debe explotar al máximo, ya que el poder aéreo produce una asimetría que debe ser utilizada." (SANTOS, 2014, p. 41).

De esta manera,"el intento de toma de Mitú en 1998, fue el final de un período de iniciativa estratégica por parde de las FARC, y fue el fracaso de su intento por pasar a una guerra de posiciones (...) la Fuerza Aérea incrementó su velocidad de respuesta y su poder de fuego, lo que hizo más vulnerable a la guerrilla en este tipo de ataques masivos" (PARDO, 2008, p. 644).

Así mismo Alfredo Rangel, establece que "se puede afirmar que la toma de Mitú marcó un punto de quiebre en la dinámica del conflicto con las FARC. A raíz de este hecho, y en particular de la operación para retomar el control del municipio, las Fuerzas Militares lograron integrar de manera efectiva el poder 
aéreo en apoyo a las fuerzas terrestres. Esta operación también fue pionera en el uso de los medios de combate nocturno." (RANGEL, 2003, p. 23). De esta forma, como lo señala Rangel también "al contar las Fuerzas Militares con medios aéreos para concentrar tropas rápidamente y proveer apoyo de fuego desde el aire, obligaron a las FARC a regresar a sus operaciones de guerra de guerrillas." (RANGEL, 2003, p. 52).

En ese sentido, la Operación Vuelo de Ángel logró frenar la estrategía militar de la organización ilegal, en la medida en que gracias a las caractéristicas inheremente estratégicas del poder aéreo, se debilitó la organización guerrillera, en cuanto a que se produjeron muchas muertes en combate de guerrilleros, y como por la guerra de movimientos, se agrupan en grandes cantidades, esto los expone ante el ataque de helicópteros o aviones como el Fantasma.

El éxito del poder aéreo con la operación Vuelo de Ángel radica en que "el poder aéreo en la guerra irregular se debe adaptar para ser efectivo, esto significa que debe identificar los nuevos centros de gravedad del enemigo y planear estratégicamente cuál es la mejor manera para derrotar al enemigo. Así, logra utilizar correctamente los instrumentos aeroespaciales. Una de las adaptaciones que debe realizar el poder aéreo es preparar a sus pilotos y demás miembros de la Fuerza Aérea, para entender los conflictos asimétricos. Cuando logran entender la forma en la que luchan las guerrillas, podrán dar golpes más efectivos. De esta forma, podrán entender que el poder aéreo en la guerra popular prolongada es más efectivo cuando se está en la guerra de movimientos, ya que en esta, la guerrilla se expone a los ataques estratégicos del poder aéreo." (SANTOS, 2014, p. 52).

Igualmente, "en consonancia con las premisas de la asimetría como estrategia, los Estados que luchan contra irregulares ven como sus ventajas son relativizadas por el enemigo. No obstante, para Colombia el hecho de contar con la supremacía aérea nunca ha dejado de ser una ventaja. Dicho de otro modo, haber alterado las ventajas relativas con las que contaba, la guerrilla por medio de la acción de la Fuerza Aérea, le sirvió al Estado para debilitarla." (JARAMILlO y STRONG, 2014, p. 18). Así se puede evidenciar, que el poder aéreo en la O.V.A. se convirtió en una herramienta militar del Estado, para recuperar el monopolio legítimo de la violencia, y así enviar un mensaje político a otras organizaciones al margen de la ley, en cuanto a que el Estado estaba preparado para repeler cualquier enfrentamiento. También se puede considerar "la Operación Vuelo de Ángel como una operación que permitió dar un salto estratégico operacional que alteró las premisas del conflicto colombiano.” (SANTOS, 2014, p. 41).

En resumen, la O.V.A implicó "misiones típicas de Defensa Aérea, Contrapoder terreste, Transporte aéreo, Asalto aéreo, Reconocimiento, inteligencia y vigilancia, así como de Comando y control." (JARAmiLlo \& STRONG, 2014, p. 16). En ese orden de ideas, la magnitud de la repuperación de Mitú "es un hito 
indispensable para entender la importancia de la superioridad aérea como un elemento clave para la libertad de acción de las Fuerzas Militares." (JARAMILLO y STRONG, 2014, p. 16).

\title{
2.3. Despúes de la Operación Vuelo de Ángel
}

Posteriormente de la Operación Vuelo de Ángel, las FFMM recuperaron su capacidad ofensiva, siendo más proactivas. Esto se ve reflejado en la medida en que después del 1998, las FFMM recuperaron su iniciativa táctica y estratégica, porque lograron proyectar operaciones militares contundentes contra la organización ilegal. Además de la transformación militar que se presentó, generando así las condiciones militares y políticas para el fortalecimiento de las Instituciones Militares.

Por ejemplo, "desde el Ministerio de Defensa, y el Comando General de las Fuerzas Militares, contando con la ayuda norteamericana se emprendió su más profunda transformación recuperando su iniciativa táctica y obligando a las FARC a retroceder (...) Con los golpes recibidos y su impacto en la institución, las Fuerzas Militares comenzaron a trabajar conceptos como los de masa y movilidad para responder a la guerra de guerrillas, lo que implicaba que la situación de confrontación se analizaba como una guerra a la que se tenía que responder con operaciones militares. (TORRES, 2008, p. 351).

Respecto a las operaciones militares relevantes, producto de esta transformación, se destacan la Operación Gato Negro y la Siete de Agosto:

\begin{abstract}
"Dos de las principales operaciones militares llevadas a cabo fueron la "Gato Negro" y "la Siete de Agosto". En la primera operación en marzo y abril de 2001, la Cuarta División, la FUDRA, la Armada y la Fuerza Aérea, en la región de San José de Ocuné, Puerto Principe, Guerima, Puerto Lindo, El Lomo, Chupabe, Cumaribo y San Felipe (Vichada) y Barrancominas (Guanía) capturaron al narcotraficante Fernandinho y tomaron un importante corredor de selva y ríos que utilizaban las farc. En agosto de 2001, aconteció la mayor operación de contrainsurgencia, después del descalabro de fines de los noventa; fue la respuesta al intento de las FARC de tomar la base de Carimagua y de recuperar el corredor que habían perdido en la Operación Gato Negro; participaron cuatro mil soldados de FUDRA, apoyados por veinte helicópteros y aviones de combate contra unos mil trescientos guerrilleros, en esta operación fue dado de baja Urias Cuella, junto con unos seiscientos insurgentes más." (ToRREs, 2008, p. 352).
\end{abstract}

Igualmente, era necesario reconfigurar las estructuras militares de las FFMM, adaptándolas al contexto de la guerra irregular. "El análisis de lo sucedido entre 1996 y 1998 llevó al estudio de la estrategia de las FARC, la que proyecta copar la cordillera oriental y en ella cercar a la capital del país (...) las Fuerzas Militares centraron su plan en la neutralización de los corredores de movilidad 
de la guerrilla, lo que afectó la estructura orgánica de las Fuerzas Militares, en tres niveles de consideración: primero se crearon los batallones de alta monta; segundo al servicio militar ingresaron miles de jóvenes del sector rural bajo la modalidad de-soldados campesinos-, y en tercer lugar, en la medida en que cerca de quinientos municipios de Colombia no había presencia de las Fuerzas militares, la estrategia de defensa proyectó y puso en marcha la actuación combinada de la policía con los militares.” (TORRES, 2008, p. 352).

Ahora bien, la transformación de las Fuerzas Militares, estuvo a cargo del General Fernando Tapias y el General Jorge Mora. "Para que pueda hablarse de transformación militar ella debe comprender tres aspectos complementarios: 1) cambios institucionales, 2) nuevas tegnologías, y 3) una nueva doctrina.' (TorRes, 2008, p. 354). El resultado de la nueva estructura orgánica de las Fuerzas Militares para los primeros cinco años del siglo XX fue el siguiente:

- Comando Conjunto Operaciones Especiales

- Coordinación Nacional de Inteligencia

- Comando Conjunto Caribe

- Fuerza de Tarea Conjunta

- Agrupación Fuerzas Especiales Antiterroristas Urbanas-AFEAUR (14)

- Batallones de Alta Montaña (7)

- Brigadas Móviles( 15)

- Grupos Gaula (32)

- Soldados Campesinos (27.000)

- Infantería de Marina (4.355)

- Escuadrones Móviles (54)

Seis divisiones Unidades Especiales (FUDRA, Brigada contra el Narcotráfico, Brigada de Aviación del Ejército, Brigada de Fuerzas Especiales) ${ }^{11}$

Toda esta restructuración militar, le dio herramientas a las FFMM para combatir a la organización ilegal. De esta manera, lograron focalizar los esfuerzos y transformarse para la guerra irregular que se vivía en Colombia.

Así mismo, "las FARC intenteron despues de Mitú, tres operaciones masivas: Puerto Rico, Meta, Casanare y San Juanito, Cundinamarca, pero fracasaron y tuvieron grandes bajas en todas ellas. A partir de esos fracasos, la guerrilla

11 Esta tabla fue sacada de (TorRes, 2008, p. 354). 
reincidió en sus ataques a pequeñas guarniciones, a pueblos desprotegidos y zonas nubladas o altas para evitar la reacción aérea." (PARDo, 2008, p. 644). Se puede evidenciar, como después de O.V.A la organización ilegal, tuvo que cambiar su modo de operar. Esto se debe a que las FFMM comprendieron las fortalezas de utilizar el poder aéreo, maximizando una debilidad de la guerrilla.

Igualmente, como lo señala Ingrid Bolívar, "desde finales de 1998, la Fuerza Pública comenzaba a mostrar alguna capacidad para neutralizar la cadena de acciones contundentes que le venían propiniando las FARC, gracias a la ventanja representada por el uso de helicópteros y aviones." (GoNZÁLEZ, BoLÍvar, y VÁSQUEZ, 2002, p. 78). En ese orden de ideas, se puede afirmar, que la Operación Vuelo de Ángel se convirtió en un predecente militar, la cual generó que las FFMM se percataran de las ventajas tácticas y estratégicas del poder aéreo.

Así mismó "durante los cuatro años (1998-2002), la relativa ventaja táctica de las FARC fue prácticamente neutralizada por la Fuerza Pública mediante el uso de la ayuda tegnológica del paquete militar incluido en el Plan Colombia y los cambios operados en los mecanismos de inteligencia del Ejército Nacional. Al golpe de Mitú contra las FARC, siguieron las acciones de la Fuerza Pública en Dabeida, en Arauca, y en el Guaviare, en las cuales los muertos de la guerrilla pasaron de 150.” (GoNZÁlez, Bolívar y VÁSQUEZ, 2002, p. 78).

En cuanto al escenario político durante y después de la retoma de Mitú, este estuvo enmarcado por el proceso de paz que se adelantó entre el Gobierno del Presidente Andrés Pastrana y la guerrilla de las FARC. "El 9 de enero de 1999, se instalaron oficialmente los diálogos de paz" (GONZÁlEZ, BolívAR y VÁSQUEZ, 2002, p. 79). Sin embargo, a principios de 1998, ya se habían iniciado los diálogos, en donde una de la exigencias de las FARC fue la desmilitarización "de los municipios de San Vicente del Caguán, La Uribe, Mesetas, la Macarena y Vista hermosa, requisito para iniciar conversaciones.” (BuitraGo, 2002, p. 151). Así, "amparado bajo la ley 418 de 1997, llamada de orden público decretó el despeje de un areá de 42.000 kilometros cuadrados por 90 días, del 7 de noviembre de 1998 al 7 de febrero de 1999." (Buitrago, 2002, p. 152).

Así se estableció después “una zona de despegue en el Caguán, que requirió once prórrogas presidenciales, objeto de negociaciones" (PALACIOS, 2012, p. 159). Esta zona de despegue comprendió los mismos municipios de San Vicente del Caguán, La Uribe, Mesetas, la Macarena y Vista hermosa.

Para la organización ilegal, "el despegue en los cinco municipios contiguos y selváticos para empezar el diálogo era una reinvidación de alto valor simbólico (...). Sin embargo, en el suroriente colombiano, el despeje del Caguán se entendió como un extraordinario triunfo político de las Farc; como un reconocimiento implícito a sus recientes victorias militares y a su poderío, la zona de despegue se convirtió en formidable arma de propaganda fariana." (PALACIOS, 2012, p. 162). 
En este sentido, vale la pena preguntarse ¿Cómo después de Mitú el Gobierno Nacional, fue capaz de entregar territorios para el despeje? Era claro que la toma de Mitú fue una estrategia política y militar de la organización ilegal, para fortalecer su posición en la mesa de negociación.

No obstante, pese a que la toma de Mitú no salió como lo planeaban, después de demostrar su capacidad militar, el gobierno le entregó ese territorio. Respecto a esto, Marco Palacios señala que "el Secretariado transmitió a las bases y simpatizantes la idea que los triunfos militares de los últimos tres años (19961998) marcaban una tendencia irreversible. En ese momento festivo no sacaron ninguna conclusión autocrítica del fiasco de Mitú." (PALACios, 2012, p. 162). Sin embargo, las FFMM mandaron un mensaje fuerte a la organización ilegal con la Operación Vuelo de Ángel, en la medida en que demostraron que estaban preparadas militarmente para repeler cualquier ataque que se presentará en el territorio colombiano.

En conclusión, la Toma de Mitú fue un intento fracasado de la organización ilegal en la guerra de movimientos. Este intento fue un fracaso por la respuesta militar de las Fuerzas Armadas enmarcada en la Operación Vuelo de Ángel. Ésta se configuró como un precedente militar para las Fuerzas Militares, sobretodo para la Fuerza Aérea Colombiana. Esto porque el poder aéreo utilizado en la Operación, maximizó las ventajas interesantemente estratégicas. De esta forma, alteró asimetrías como el pie de fuerza de la organización guerrillera, la estrategia militar de crear un corredor estratégico, entre otros. Igualmente, permitió que las FFMM entendieran la importancia del poder aéreo como una herramienta militar y política para debilitar al enemigo. Después de la Operación Vuelo de Ángel, las Fuerzas Militares fueron más proactivas, porque lograron demostrar su capacidad militar para neutralizar a las organizaciónes ilegales. Esto se ve reflejado en la medida en que las FFMM lograron maximizar la ventaja del uso de aviones de ala rotatoria y ala fija, prueba de ello fueron las acciones militares de la Fuerza Pública en las operaciones Gato Negro, y Siete de Agosto.

\section{CONCLUSIONES}

Este trabajo se propusó analizar porque la operación Vuelo de Ángel fue uno de los puntos de inflexion del conflicto armado. Esto por el poder aéreo demostrado, que logró alterar las asimetrías de poder entre las FFMM y la organización ilegal.

En ese orden de ideas, siguiendo las premisas del conflicto armado colombiano se encontró que éste ha estado caracterizado por los enfrentamientos entre el Estado y grupos al margen de la ley. De esta manera, se presentaron puntos de inflexión históricos, como la violencia bipartidista del siglo XIX, el Bogotazo, la Operación Marquetalia, entre otros. Desde este momento, se empezaron a gestar problemas económicos, inestabilidad política, violencia, y exclusión política. En 
los años sesenta bajo el contexto de la Guerra Fría, y en donde las ideologías marxistas y leninistas estaban en furor, se crearon, grupos al margen de la ley, conocidos como las guerrillas de las FARC, ELN y el EPL. En ese sentido, la organización ilegal FARC se configura como un actor irregular, que bajo la tesis de la guerra popular prolongada y la combinación de todas las formas de lucha, empiezan a gestar ataques contra el Estado Colombiano.

Es así, que durante los años noventa, se presentaron diferentes ataques militares por parte de las FARC, cambiando la dinámica de la violencia. En esa época, el Estado Colombiano tuvo problemas para mantener su monopolio legítimo de la violencia, ya que al tener que enfrentarse con grupos ilegales, estos cuestionaron esa capacidad estatal propia del Estado de Derecho. Igualmente, siguiendo los planteamientos estratégicos de la organización ilegal bajo la Séptima Conferencia y la Octava Conferencia, se estructuraron como grupo armado ilegal, con un modo de operar diferente, y en donde entienden la necesidad estratégica de controlar territorios. Así pues, en los años noventa, realizan diferentes golpes en el sur del país, como los ataques a Las Delicias, El Billar, Miraflores y Mitú. Estos ataques tienen un factor común, fueron enfrentamientos prolongados, con armamento pesado (artillería) y los objetivos militares son estratégicos. Además, en los noventa, la organización ilegal se encuentraban en la guerra de movimientos de la guerra popular prolongada, la cual les permitió agruparse y atacar unidades militares especializadas.

Ahora bien, uno de los resultados del análisis de la década de los años noventa, con los ataques a Las Delicias, el Billar, Miraflores y Mitú, se infiere que la guerrilla quería controlar esos territorios para crear y mantener un corredor de movilidad hacia las fronteras de Venezuela y Brasil. Esa línea estratégica que se traza uniendo los puntos, permite visualizar ese control de territorios. Igualmente, con la desmilitarización y después el despeje de territorio en la zona de distensión, se evidencia que la organización ilegal mediante sus estrategias políticas, pretendía también obtener territorios, pero por vía política.

Otro resultado de la investigación demostró que cuando la organización ilegal lanza la Toma de Mitú, esta tenía un carácter estratégico de alto valor, ya que en primer lugar, es una capital de departamento en una zona estratégica. En segundo lugar, la guerrilla quería fortalecer su posición política en la mesa de negociación con el Gobierno del Presidente Andrés Pastrana y tercero, al controlar el territorio, le demostrarían a la comunidad internacional su capacidad bélica, con el propósito de obtener el estatus de beligerancia. También, le querían demostrar al Estado y a las FFMM su capacidad militar y el control territorial. La organización ilegal estaba desgastando al Estado al propiciar ataques en todo el territorio colombiano, por ende al realizar la toma de Mitú mandaban un mensaje político (estamos en todo el territorio), a comparación del Estado en donde en muchos lugares, no había presencia estatal. 
Sin embargo, las FFMM en cabeza de la Fuerza Aérea Colombiana, lanzan la Operación Vuelo de Ángel, para retomar Mitú. Uno de los resultados más relevantes de la investigación radica en que esta Operación fue clave para recuperar Mitú, ya que gracias a la utilización de los instrumentos aeroespaciales, las FFMM lograron alterar asimetrías de la organización ilegal, como el pie de fuerza, y otros cálculos estratégicos. La Operación Vuelo de Ángel también logró cambiar la estrategia militar de la organización ilegal de pasar de la guerra de guerrillas a la guerra de movimientos, en la medida en que la guerrilla se dio cuenta que al estar agrupadas, quedan expuestas al poder aéreo. Quizá por esta razón, se puede considerar que la O.V.A es uno de los puntos de inflexión en el Conflicto Armado Colombiano, porque al cambiar la estrategia militar de la organización ilegal, estas tuvieron que volver a la guerra de guerrillas para poder realizar ataques contra el Estado. Esta operación cambió las dinámicas del conflicto, obligando a la organización ilegal a realizar emboscadas y otras tácticas propias de guerra de guerrillas. Por estas razones, se puede considerar la Operación Vuelo de Ángel, como un punto de inflexión que logró alterar la estrategia de la organización ilegal, así como cambiar la balanza de poder entre las FFMM y la guerrilla, favoreciendo al Estado Colombiano.

Después de Mitú, pese a que las FARC perdieron en términos militares, ganaron en términos políticos, dicho de otro modo, el ataque a Mitú, les permitió fortalecer su posición política en el proceso de paz con el Gobierno Pastrana y obligaron al Estado a sentarse a dialogar. Sin embargo, las FFMM con la O.V.A tuvieron muchas lecciones aprendidas y se dieron cuenta que la ventaja táctica y estratégica del poder aéreo, podía ser clave para ganar batallas. De esta forma, la Operación Vuelo de Ángel, se convirtío en un precedente histórico y militar que marcó el Conflicto Armado Colombiano. En ese orden de ideas, el poder aéreo se configuró como una herramienta militar para el Estado, para recuperar su monopolio legítimo de la violencia.

\section{REFERENCIAS}

GonzÁlez, F. E. (2002). La dinámica del conflicto . En: F. E. González, Violencia política en Colombia de la nación fragmentada a la construcción del Estado (pp. 41-92). Bogotá: CINEP.

Jaramillo, M., y Strong, J. (2014). La Fuerza Aérea Colombiana, Punta de lanza de la defensa de la nación . En: La Fuerza Aérea Colombiana y sus nuevos retos. Campos de acción en un escenario interno transformado (pp. 9-58). Bogotá: Escuela Superior de Guerra.

LosADA, R. y Casas. Enfoques que privilegian las Instituciones. Enfoques para el análisis político. (pp. 163-178) Bogotá: Pontificia Universidad Javeriana, 2008. 
Leal, Francisco (2002). ¿Seguridad Nacional, Regional o de Estados Unidos? La seguridad nacional a la deriva (pp. 144-188). Bogotá: Alfaomega.

Palacios, M. (2012). Paz cuatrienal, Violencia pública en Colombia, 1985-2010 (p. 220). Bogotá: Fondo de Cultura Económica.

PATIÑo. (2010). Estado y Guerra, Guerra y construcción del Estado en Colombia 1810-2010. (p. 303) Bogotá: Random House.

PARDO, R. (2008). La transformación de la guerra, La historia de las guerras (pp. 625-649). Bogota: Ediciones B.

Pastrana, A. (2005). Capítulo IX el día que cambió la guerra. La palabra bajo fuego (p. 554). Bogotá: Planeta.

Perdomo, Y.(2006). La Operación Vuelo de Ángel: la retoma de Mitú. En G. Osorio Martínez(Comp.) Hablan los generales las grandes batallas del conflicto Colombiano contadas por sus protagonistas (pp. 298-306). Bogotá: Editorial Norma.

Torres ,C. (2008). Conflicto interno y Fuerzas Armadas Colombianas. En C. Torres del Río y S. Hernández (Eds), De milicias reales a milicias contrainsurgentes. (pp. 339-361) Bogotá: Editorial Pontificia Universidad Javeriana.

Artículos en publicaciones periódicas académicas

ECHANDÍA, C. (2008). El fin de la vulnerabilidad de las FARC. El estado actual del conflicto armado en Colombia. Nueva Sociedad, 217, 1-10. Disponible en:http://www.nuso.org/upload/articulos/3543_1.pdf

GeISs, R. (2006). Las estructuras de los conflictos asimétricos. En: International Review of the Red Cross, (864):1-24 Disponible en http://www.icrc.org/spa/ assets/files/other/irrc_864_geiss.pdf

MARTín, JE., Jaramillo-Marín, J. (2014). Las conmemoraciones noticiosas en la prensa colombiana: rememorando la toma a Mitú, Palabra Clave 17(2):378-411. Disponible en http://palabraclave.unisabana.edu.co/index. php/palabraclave/article/view/3561/3504

Rawley. (1967). Turning Points of the Civil War. Review Book. The Journal of Southern History 33 (3) , pp. 411-412 Disponible en http://www.jstor.org/ stable/2204893

Roberti, E. (2012). El enfoque biográfico en el análisis social: claves para un estudio de los aspectos teórico-metodológicos de las trayectorias laborales, En: Revista Colombiana de Sociología. RCS 35 (1) Disponible en http:// www.revistas.unal.edu.co/index.php/recs/article/view/31341/39585

OrJUELA, L. (1998). El Estado colombiano en los noventa: entre la legitimidad y la eficiencia. Revista de Estudios Sociales,(1) :56-60. Disponible en http:// res.uniandes.edu.co/view.php/28/index.php?id=28 
PUBLICACIONES PERIÓDICAS NO ACADÉMICAS

ECHANDÍA, C. (2011). Situación actual de las FARC: Un análisis de los cambios en las estrategias y la territorialidad (1990-2011). Verdad Abierta. Disponible en www.verdadabierta.com/documentos/.../farc-1/270-situacion-farc-web1

Fundación Ideas para la Paz (2015). Hoy y ayer del Bloque oriental de las Farc Áreas Dinámicas del Conflicto y Negociaciones de Paz marzo de 2015, Fundación Ideas para la Paz: Disponible en http://cdn.ideaspaz.org/media/ website/document/552d4149f0d72.pdf

HaYward, J. (2009). Air Power, Insurgency and the War on Terror. Royal Air Force Centre for Air Power Studies: Disponbible en http://www.joelhayward. org/Hayward\%20Insurgency\%20Book\%20\%20A5\%20We b.pdf

METz, S., y Johnson II. (2001). Asymmetry and U.S military strategy: Definition,Background and Strategic concepts.Strategic studies institute. Disponible en http://www.strategicstudiesinstitute.army.mil/pubs/display.cfm?pubID=223

Ogan, A. J. (1991). Reflexionando sobre el poder aéreo. Air and Space Power Journal Disponible en http://www.airpower.maxwell.af.mil/apjinternational/ apjs/1991/1trimes91/ogan.html\#ogan

Peck, A. G. (2007). La Función Crucial del Poder Aéreo en la Guerra Irregular (IW). En: Panzertruppen. Disponible en: http://www.panzertruppen.org/ documentos/poderaereo.html

RANGEL, A. (2003). Fuerzas militares para la guerra. La agenda pendiente de la reforma militar. Fundación Seguridad y Democracia : Disponible en http:// www.aporrea.org/media/2009/11/fuerzas_militares_para_la_guerra.pdf

SAntos, M. (2014). La Operación Vuelo de Ángel, el poder de la Fuerza Aérea Colombiana y el cambio en la asimetría de poder entre las FFMM y las FARC: Repositorio Universidad del Rosario Disponible en http://repository.urosario. edu.co/bitstream/handle/10336/8913/1020765037-2014.pdf?sequence $=7$

\section{Otros documentos}

El Espectador. (2008, julio 19). Así fue la toma de la base de Miraflores. El Espectador: Disponible en http://www.elespectador.com/noticias/nacional/ articulo-asi-fue-toma-de-base-de-miraflores

Perdomo (2013) Operación Vuelo de Ángel. Doctrina y Empleo del Poder Aéreo Aplicación de la Fuerza (Presentación en Power Point) Escuela Superior de Guerra.

Siglo, E. N. (2012, diciembre 12). Misiles en poder de Farc: ¿mito o realidad? Recuperado el 12 de noviembre 2015,El Nuevo Siglo: Disponible en http://www. 
elnuevosiglo.com.co/articulos/12-2012-misiles-en-poder-de-farc-\% $\% 2 \% B-$ Fmito-o-realidad.html

Tiempo, E. (1990, diciembre 10). El Ejército ataca Casa verde. Consultado el noviembre 8, 2015, El Tiempo: Disponible en http://www.eltiempo.com/ archivo/documento/MAM-34015

Universidad de Valencia. (s.p). Método Cualitativo. Recuperado el 21 de noviembre de 2015, de Universidad de Valencia: Disponible en http://www. uv.es/monterdh/researchers/Curso_Master_UJI/(5a)Metodos_de_investigacion_social_Cualitativos.pdf 